\title{
Evaluation OF MOdels To IMPLEMENT THE ISO 9001 PROCESS APPROACH
}

\author{
Nuha El-Khalili \\ Department of Software Engineering, University of Petra, Amman, Jordan
}

\begin{abstract}
The ISO 9001 standard is adopted worldwide by organizations from different sectors. The ISO 9001:2015 guidelines for implementing the process approach require not only the identification of the organization processes, but also the description of their interactions as a network system. Flow charts are a common tool adopted in quality management to show the sequence flow of a process. However, they do not show interrelations between different processes. The first aim of this study is to investigate the utilization of some software engineering models to satisfy the process approach requirement in the ISO 9001:2015 standard. The second aim is to show the implementation of the ISO 9001:2015 process approach and the "Plan-DoCheck-Act" (PDCA) cycle to manage academic programs processes as a case study and to present how the proposed models can be utilized to describe the interactions between processes. Finally, the study used a semi-structured interview methodology to evaluate the proposed models based on three criteria: understandability, modifiability and process improvement.
\end{abstract}

\section{KEYWORDS}

ISO 9001:2015; process approach; Software engineering models; Academic Program Management; semistructured interview

\section{INTRODUCTION}

Adopting ISO 9001 standard inflects many benefits for an organization such as clear structure of processes, tasks and responsibilities inside the organization, which facilitate decision making and improvements to achieve efficiency. All these benefits lead to an increase in the quality of the organization's services. The percentage of the adoption of the ISO 9001standared has been fluctuating worldwide over the years since 1993. The number of certificates issued in 2017 was $1,058,504$ [1].

There are three core concepts in the ISO 9001: 2015: the process approach, risk-based thinking, and management of the processes using "PDCA". Usually, when implementing the process approach, identifying the processes in the organization is intuitive. However, describing the interrelations between processes is usually overlooked. This paper proposes the utilization of four different software engineering models that organizations can use to represent the relations between processes, hence satisfying the process approach requirement. Then, we evaluate the proposed models to assess the usefulness of each model in understanding the interrelations between processes, modifying them and facilitating process improvement. The second goal of this paper is to demonstrate the applicability of the ISO 9001:2015 standard within Higher Education Institutes (HEI) to manage academic programs processes. We show the implementation of the process approach within the PDCA cycle for managing academic programs processes and we present the utilization of the proposed models in this case study. 
In the next section, an overview the important concepts of ISO 9001 related to this study is presented. Section 3 presents a literature review of studies reporting the utilization of tools and models for the implementation of ISO 9001. We also review studies which utilize ISO 9001 for academic program management in higher education. Then, section 4 presents the different models to represent the interaction between processes. Section 5 introduces the design process of the academic program (AP) quality management system and we present the implementation of the proposed models in this case study. Finally, section 6 reports the evaluation process of the presented models and its results.

\section{IsO 9001:2015}

Clause 4.4 in ISO 9001: 2015 standard has emphasized the need to identify for each process: input, output, measurements and related performance indicators, responsibilities and authorities, risks and opportunities. This is later explained in $[2,3]$ by the process approach guidelines. The process approach was promoted in ISO 9001:2008. Then it became a requirement in ISO 9001:2015. The process approach integrates processes into a complete system to achieve strategic and operational objectives. The guidelines explain that the process approach is implemented within the general Plan-Do-Check-Act (PDCA) cycle. This cycle ensures the continuous improvement of the organization processes. In the plan stage, the objectives and processes necessary to deliver results to satisfy stakeholders are set. The "Do" stage implements what was planned. In the "Check" stage, monitoring and measuring processes are done. Finally, actions to improve the performance of processes are taken in the "Act" stage.

A process is defined in this paper (as in the ISO standard) as a "set of interrelated or interacting activities that use inputs to deliver an intended result" [3]. The ISO guideline explains that the first step when applying the process approach is to define the organization processes. Then, the next step is to describe the network of processes interactions. The guideline suggests using tools such as modelling, diagrams, matrices and flowcharts to achieve this step.

\section{LITERATURE REVIEW}

\subsection{Using tools and models in ISO 9001}

The flow chart model is commonly used in quality management systems to show the sequence flow of one process. However, very few studies presented tools or models to show the relationships between processes in a system for the purpose of satisfying the ISO 9001 standard. An early study presented a generic method for implementing ISO 9001 in a project management environment using the process management approach. The study recognizes the importance of depicting a visual baseline model of the organization processes and presents an example of such a model for the project life cycle. However, the proposed model in this study does not follow any standard notation [4]. Marques and Requeijo discuss how a Six Sigma tool, specifically "Suppliers, Input, Process, Outputs, and Customers" (SIPOC) diagrams, can be used to map interrelating and managing key processes of an organization to achieve the process-based model of the ISO 9001:2008 standard. They present an example of a network of processes, which shows arrows of output of one process being the input of other processes [5].

\subsection{ISO 9001 in education}

According to the ISO survey published in 2017, which provides detailed statistics of the certified organizations around the world sorted by industrial sectors, the percentage of organizations in the education sector from 2005 till 2017 was only around 2\% of the total ISO 9001 certificates issued 
[1]. In the 90s, a lot of debate surrounded the application of ISO 9000 (formerly known as British Standard BS 5750) in education. There was scepticism that the process of formalizing and documenting educational processes does not ensure quality [6,7]. So, when Thonhauser and Passmore surveyed American and British education institutions in 2006, very few universities were found to implement ISO 9000 (mainly vocational education and training providers); and if a university was found implementing it, it was usually in certain departments or programs, but not in the entire university. Two of the reported causes are that the implementation of ISO 9000 is optional for educational institutes in addition to its high cost [7]. Another reason is the widespread criticism of interpreting key terms of the ISO standard, which were devised originally for business, to suite education (such as product and customer) [8]. ISO has realized the frail participation of the education sector in adopting ISO, so ISO published IWA (Internal Workshop Agreement) 2 Quality management systems - Guidelines for the application of ISO 9001 in education in 2007 and the ISO 9001:2008 Handbook for Educational Organizations. The handbook explains the implementation of the ISO 9001:2008 within educational institutes and defines key terms within this context. The handbook also lists examples of educational processes and tools that can be used such as flow charts, control graphs and cause and effect diagrams [9].

Literature has very scarce reports of successful implementation of ISO 9001 in the education sector such as [10,11]. Ariff, Zaidin, and Sulong describe concerns and challenges while implementing the quality Assurance (QA) system on academic programs at the Universiti Teknologi Malaysia. One of these concerns is how to merge the requirements of ISO 9001:2000 with the QA criteria enforced by the Ministry of Higher Education in Malaysia. They have mapped each QA criteria with the corresponding ISO clause and suggested an extended process model of ISO 9001:2000 to merge both systems. They also have raised a concern of the challenge of coordinating and integrating academic management activities with the other university services in order to achieve the university objectives [12].

A more recent study by Levina et. al. stresses the need for Total Quality Management to improve education and to use process models for educational activities to allow continuous improvement. They also present an example of an interaction network of processes in an educational organization that follows the PDCA cycle [13].

\section{Proposed Models}

Software Engineering analysis models are used to understand the analysed system and to show the relationships between parts of a system. Thus, it is intuitive to utilize them to implement the process approach requirement. Some software analysis models show the flow of one process such as the flow chart and the Unified Modelling Language (UML) activity diagram. But since the scope of these models are only one process, they do not help in showing the system as a network of processes.

In the following subsections four models used in software engineering to represent the relations between processes are proposed.

\subsection{Business Process Model}

Process maps come in many different forms, but they tend to use SIPOC (a Six Sigma diagram for Suppliers, Input, Process, Outputs, and Customers) format or UML (Unified Modelling Language) standard as notations.

The Business Process Model (BPM) is a graphical notation for specifying business processes. The standard is maintained by the Object Management Group (OMG). It was first released in 2004 
and the latest version (2.0) was released in 2011. It depicts the flow of processes in an organization (or the flow of tasks in a process), as well as responsibilities (represented as lanes and pools), and artifacts (or data objects) [14].

\subsection{Cross Reference Matrix}

It is common in software engineering to use tools to achieve requirements traceability, such as the traceability matrix. Using this tool, all system requirements are listed in tabular format horizontally and vertically to form a matrix. Related requirements are indicated with symbols placed at their crossing cells. Extending the use of the traceability matrix to show the relationships between procedures in a system would also achieve the process approach requirement. Using a spreadsheet to create a cross reference matrix of the relationship between requirements is one way to facilitate the analysis and change decisions when managing requirements [15].

Even more, requirements management Computer Aided Software Engineering (CASE) tools can be utilized for this purpose. The advantages achieved by utilizing requirements management tools to store ISO procedures are as follows:

- A common repository of all procedures with multiuser access to them with different authorization privileges.

- Track the historical changes of the ISO procedures and the rational of change.

- Utilize traceability capabilities to show relationships between procedures.

\subsection{Reference Model}

The visual representation of how procedures reference each other is more intuitive to follow than the cross-reference matrix but has the same advantage as knowing the effect of changing one procedure on the others. Also, when the number of processes in the organization is large, the cross-reference matrix becomes difficult to use and maintain. Alternatively, we propose another reference model which uses the UML notation. Processes are represented as tasks as in the BP model and are categorized into the PDCA cycle. The four categories PDCA of the processes are represented as pools or lanes. Then relations of interest are represented as lines between processes.

\subsection{Data Flow Diagrams}

Data flow models are used to show the flow of input/output data within processes of a system, hence showing their interrelations. The notation of this model can be used to show the interrelation between ISO procedures, where procedures are represented as system processes and required input/output from one procedure to the other is represented as data flows. This also helps in estimating the effect of change on the system.

\section{Academic Program Management: A Case Study}

In this section, we apply the proposed models to managing the academic programs procedures. As previously mentioned, instances of applying the ISO standard in the education section were very few, so we are interested in showing the applicability of the ISO 9001:2015 standard in managing procedures that control the higher education Academic Process (AP). 
In order to design the AP quality management system, the QA office team identified academic processes already implemented at the university, which were mainly categorized under the "Do" stage. In order to complete the PDCA cycle, planning processes to initiate new academic programs (AP) as well as measurement and improvement processes were designed. Hence, all the university AP management processes were categorized into the PDCA cycle. The total number of processes is 26; table 1 shows the processes names and categorization.

Table 1: Academic Program Management Processes

\begin{tabular}{|c|c|c|}
\hline Category & Process Name & Process ID \\
\hline \multirow{5}{*}{$\begin{array}{l}\text { Planning } \\
\text { (Plan) }\end{array}$} & Feasibility study for a new AP & $\mathrm{P} 1$ \\
\hline & Initiating a new AP & $\mathrm{P} 2$ \\
\hline & Program design/re-design & $\mathrm{P} 3$ \\
\hline & $\begin{array}{l}\text { Preparing and revising AP intended learning } \\
\text { outcomes (ILOs) }\end{array}$ & P4 \\
\hline & $\begin{array}{l}\text { Preparing and revising Course intended learning } \\
\text { outcomes (ILOs) }\end{array}$ & P5 \\
\hline \multirow{15}{*}{$\begin{array}{l}\text { Implementation } \\
\text { (Do) }\end{array}$} & Preparation of semester classes schedule & D1 \\
\hline & Course management & D2 \\
\hline & Preparation of final exams schedule & D3 \\
\hline & Final exam time change process & D4 \\
\hline & Preparation of exams and proctoring schedule & D5 \\
\hline & Multi-sections courses coordination & D6 \\
\hline & Final exam preparation & D7 \\
\hline & Students absence and fail by absence & D8 \\
\hline & Books and references acquisition & D9 \\
\hline & Catching a cheating incident & D10 \\
\hline & Exams proctoring & D11 \\
\hline & Academic advising & D12 \\
\hline & Follow-up of academically hindered students & D13 \\
\hline & Follow-up of learning resources & D14 \\
\hline & Electronic exams preparation & D15 \\
\hline \multirow{3}{*}{$\begin{array}{l}\text { Measurement } \\
\text { (Check) }\end{array}$} & Program efficiency measurement & $\mathrm{C} 1$ \\
\hline & Course assessment and modification & $\mathrm{C} 2$ \\
\hline & Stakeholders program assessment & $\mathrm{C} 3$ \\
\hline \multirow{3}{*}{$\begin{array}{l}\text { Improvement } \\
\text { (Act) }\end{array}$} & AP modification & $\mathrm{A} 1$ \\
\hline & AP suspension or abrogation & A2 \\
\hline & AP management procedure modification & A3 \\
\hline
\end{tabular}

Although all ISO procedures related to service departments' management are documented as flow charts, the AP management processes are documented as text. This is due to the following reasons:

- The main audience of academic procedures are academic staff which are accustomed to reading text and are mostly unfamiliar with flow chart notations.

- Academic procedures tend to be long with multiple roles involved, which make flow charts more complex to follow.

- Steps of these procedures need to be elaborated with long text to avoid ambiguity, which make the flow chart symbols cluttered with text. 
The procedures of processes were published in a booklet for interested parties. Shortly after this design process, the need for a visual view of the relationships between processes became clear. Among the reasons for this emerging need were the revision of some processes and the addition of new ones, which raised questions about how these changes would affect other processes. Another reason was the change of the design team that originally devised the processes, so clear communication between the two teams was necessary to insure a smooth transition.

\subsection{Tools to represent processes interactions}

In the following subsections, we apply the proposed tools to represent the interrelationship between the AP processes. There are two objectives for using these tools that we would like to achieve:

- First, to provide a clear overview of the network of processes involved in academic program management and their interactions.

- Second, to facilitate the analysis and decision-making process when improving the processes.

\subsubsection{Business Process Model}

In order to utilize the BPM notation, the procedures were manually traversed to represent the relationships between them. Each process was represented as a task. Sequence Flow connections showed the order of performing the procedures. Association connection linked rules and guidelines (represented as artifacts) to their appropriate processes. Parallel processes were represented as forks. Figure (1) shows a BPM for the processes of the AP quality management system.

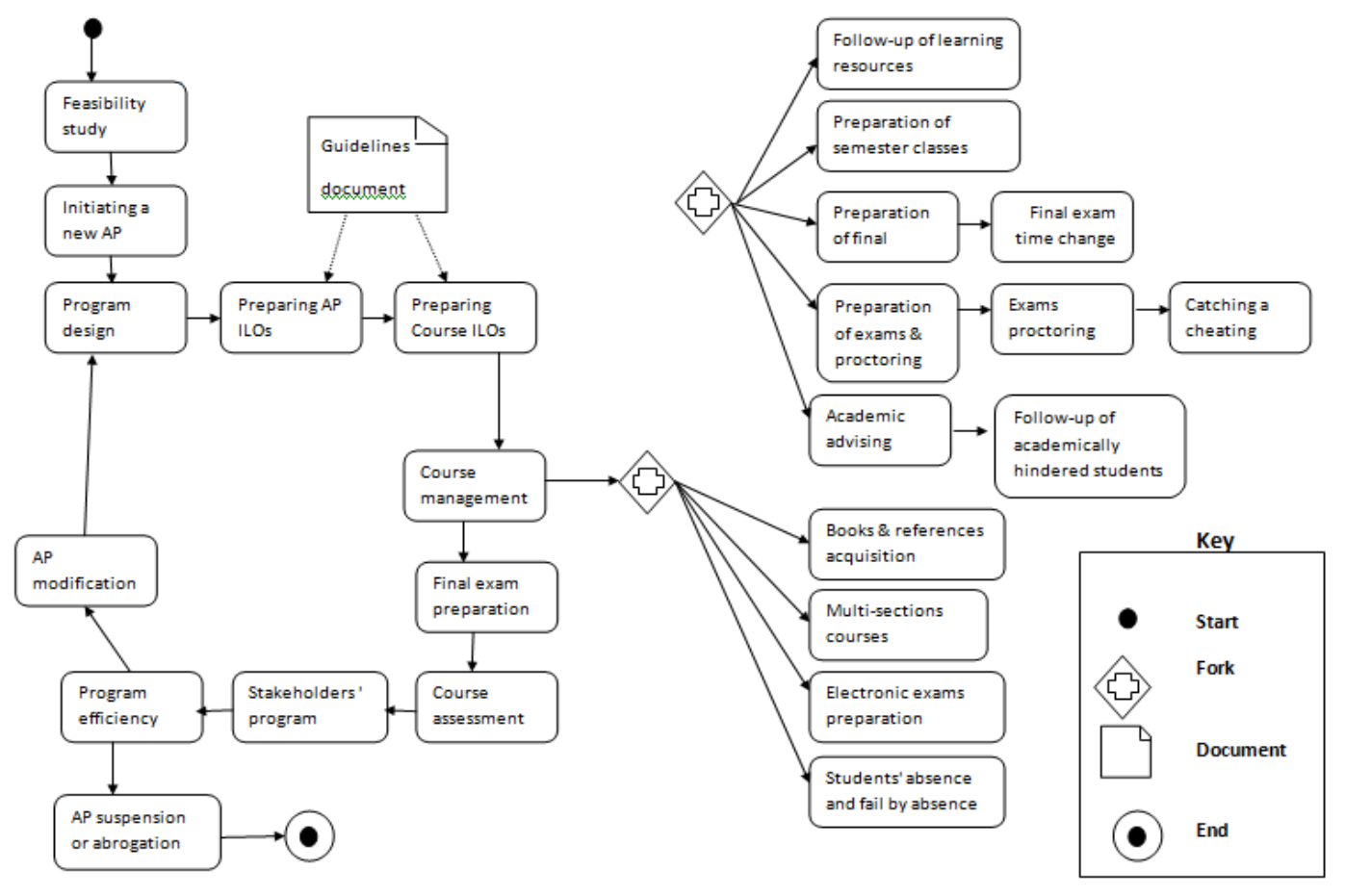

Figure (1): BPM for AP processes 
The arrows show the sequence of processes execution. Two artifacts are represented in the model as examples of data objects interacting with processes. Other forms and documents needed for each process could have been added, but we preferred not to clutter the model with details that might hinder understanding it. It is obvious from this model the closed cycle formed by the PDCA processes.

\subsubsection{Cross Reference Matrix}

In applying the cross-reference tool to the AP management process, we first identify each process with a unique ID as shown in table (1). Then, we list all processes in the rows and columns of the matrix as shown in figure (2). Choosing suitable notations to represent the relation between processes depends on what types of relations are of interest to the design team. The example shown in figure (2) uses " $\mathrm{R}$ " to mean an unidirectional reference between the two processes, while the "B" means a bidirectional reference. For instance, process p3 "program design" has a reference to process p5 "preparing course ILOs", so letter " $\mathrm{R}$ " is written in this cell. Meanwhile, process $\mathrm{p} 3$ has a reference to process $\mathrm{p} 2$ "initiating a program" and $\mathrm{p} 2$ has reference to $\mathrm{p} 3$, so the cell has the letter "B" inside it. This is helpful when making changes to one process to identify affected processes.



Figure (2): Cross reference matrix to the AP processes

\subsubsection{Reference Model}

Figure (3) shows a visual representation of the cross-reference matrix, where AP processes are represented as tasks in the business process model notation and are categorized into pools according to PDCA cycle. A bidirectional (solid) arrow between two tasks means that both processes reference each other. Meanwhile, an unidirectional (dashed) arrow means that the source task references the destination task. 
International Journal of Software Engineering \& Applications (IJSEA), Vol.10, No.2, March 2019

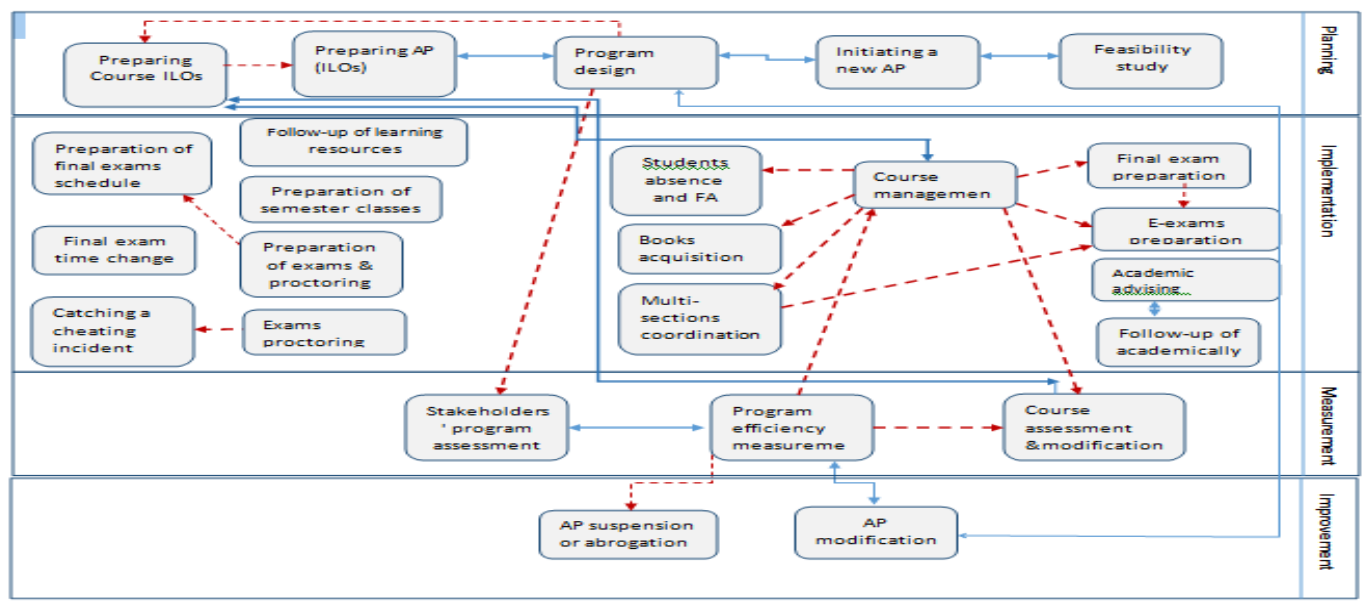

\subsubsection{Data Flow Diagram}

Figure (3): references model between processes

Data flow diagrams (DFD) have no interest in showing the sequence of processes execution, rather they focus on showing input/ output from one process to the other. A complete detailed DFD for the AP management system is not of interest here. However, an overview DFD is what we propose. Figure (4) shows a general DFD representation of the AP processes that shows high level data moving between them. External entities represented in the model are examples of service departments at the university and their interactions with the processes.

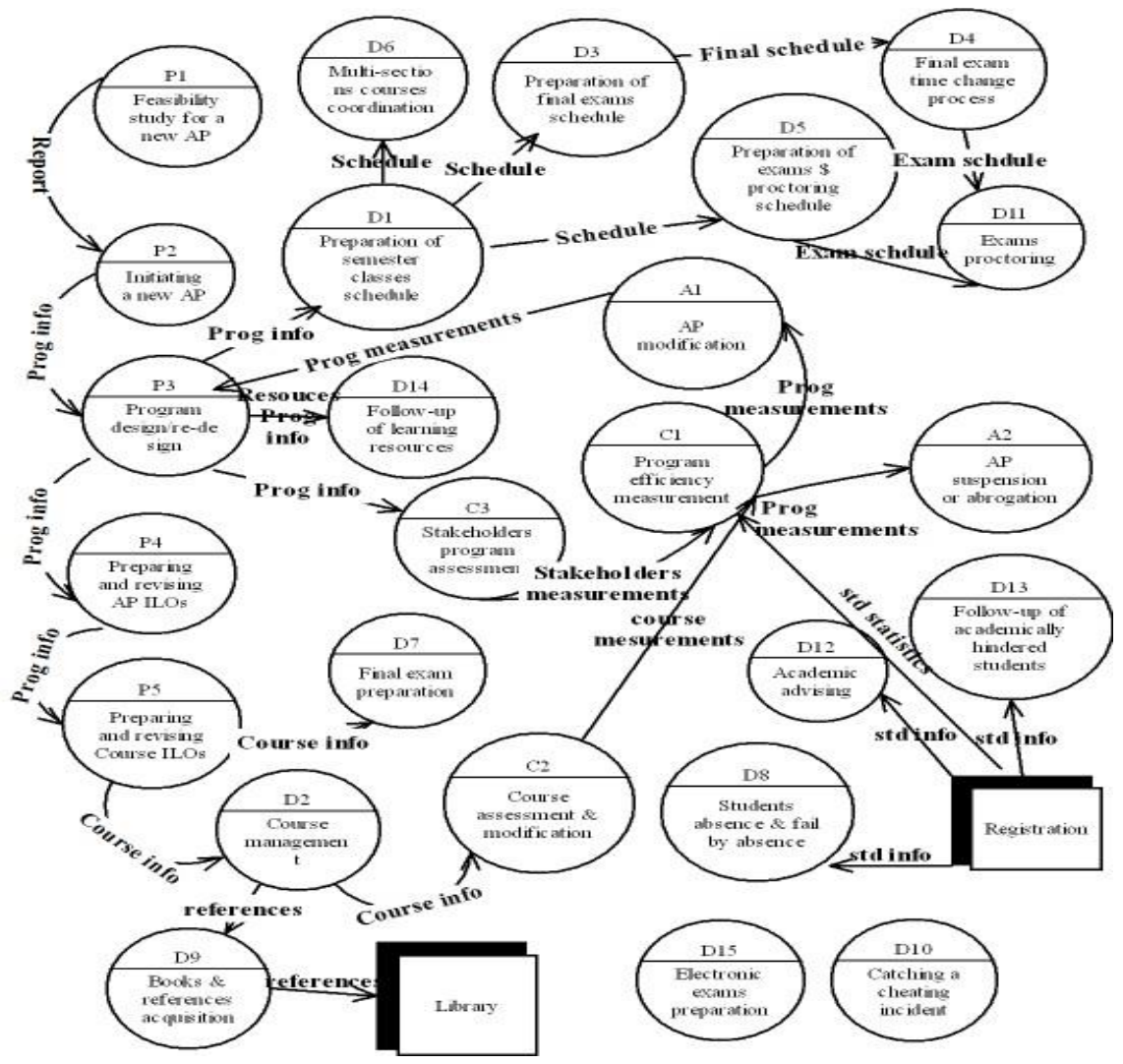

Figure (4) General DFD representation of the AP processes 


\section{Evaluation}

Literature has few studies that evaluate software engineering models. The most recent one, which includes earlier studies is a study by Garcia-Garcia and others. In this study ten software process modelling languages have been compared and their advantages and disadvantages have been evaluated in order to facilitate the decision of an organization to choose the most suitable one. The quality model proposed to evaluate the software process modelling languages considered five common criteria that have been reported in literature before, which are: expressiveness, understandability, conformity to standards, granularity, and executability. They also proposed five new criteria to be considered, which are: orchestration, measurability, business rules support, supporting tools, and validation in real environments [16].

In this section, we present an evaluation of the presented model in section 4. The aim of the evaluation process is to identify the degree each proposed model achieved the intended objectives. Thus, the evaluation criteria that we used are: Understandability, Modifiability, and Process improvement. The first criterion- Understandability- refers to the degree the model helps in understanding the relations between procedures. The second criterion- Modifiability -refers to the degree the model helps when making changes to procedures. The last criterion-Process improvement- refers to the degree the model helps in making decisions for process improvements.

The intended users for these tools are experts who are limited in number and have limited time to take part in evaluation studies. Furthermore, in order to be able to evaluate the models' pros and cons, they need to use them in expected process improvement situations. A semi-structured interview methodology was employed since it is a qualitative research tool used to explore people's experiences and understandings, and often yield more detailed information than quantitative methods.

Four members of the quality assurance design team (1 male and 3 females) participated in the evaluation process. They are all academic staff members from different disciplines with experience in quality assurance work in education. They are aware of the AP management processes and have had access to the text description booklet of the procedures. Each participant was interviewed individually. At first, the members were asked questions about their familiarity with the relationships between processes, and the effect of changing one process on others. They were asked to answer these questions based on their knowledge and using the written procedures only. All participants unanimously agreed that it is difficult and time consuming to find these relations using the current text description.

Next, the proposed models were explained to them. The members where presented with what-if cases where certain procedures need improvement or change, and they were asked to use the models to suggest the proper management of these changes.

The members were asked to evaluate each model according to three criteria using a four-level scale (1-excellent, 2-good, 3-acceptable, and 4-poor). Table 2 shows the percentages given to each model in each criterion. 
International Journal of Software Engineering \& Applications (IJSEA), Vol.10, No.2, March 2019

Table 2 Evaluation results given to each model in each criterion

\begin{tabular}{|l|l|l|l|l|}
\hline Criterion & $\begin{array}{l}\text { Model 1 } \\
\text { (BPM) }\end{array}$ & $\begin{array}{l}\text { Model 2 } \\
\text { (Cross reference } \\
\text { matrix) }\end{array}$ & $\begin{array}{l}\text { Model 3 } \\
\text { (references } \\
\text { model) }\end{array}$ & $\begin{array}{l}\text { Model 4 } \\
\text { (DFD) }\end{array}$ \\
\hline Understandability & Excellent 50\% & $\begin{array}{l}\text { Excellent 25\% } \\
\text { Acceptable 25\% }\end{array}$ & $\begin{array}{l}\text { Excellent 25\% } \\
\text { Acceptable 25\% }\end{array}$ & $\begin{array}{l}\text { Excellent 25\% } \\
\text { Acceptable 25\% }\end{array}$ \\
\hline Modifiability & $\begin{array}{l}\text { Excellent 25\% } \\
\text { Good 25\% }\end{array}$ & $\begin{array}{l}\text { Excellent 25\% } \\
\text { Good 25\% }\end{array}$ & Excellent 50\% & $\begin{array}{l}\text { Excellent 25\% } \\
\text { Good 25\% }\end{array}$ \\
\hline $\begin{array}{l}\text { Process } \\
\text { improvement }\end{array}$ & Excellent 50\% & $\begin{array}{l}\text { Excellent 25\% } \\
\text { Good 25\% }\end{array}$ & $\begin{array}{l}\text { Excellent 25\% } \\
\text { Good 25\% }\end{array}$ & $\begin{array}{l}\text { Excellent 25\% } \\
\text { Good 25\% }\end{array}$ \\
\hline
\end{tabular}

The results of the evaluation show that the business process model was thought to be the most useful tool for understandability (50\% voted excellent), while the rest of the models do not help as much in understanding the relations between procedures. In terms of modifiability, the reference model was thought to be the most helpful model when making changes on procedures (50\% voted excellent). Finally, the business process model was thought to be the most useful when making decisions for process improvement (50\% voted excellent).

\section{CONCLUSION}

The contribution of this work is twofold: first we proposed four models to represent the relationships between processes in a system to achieve the process approach of the ISO 9001:2015 standard, then we evaluated them according to three criteria: understandability, modifiability and process improvement. The results of the evaluation showed that the business process model was thought to be the most useful tool for understandability and process improvement, while the reference model was thought to be useful for modifiability.

Secondly, we illustrated how ISO 9001:2015 standard is applied to the higher education sector to manage processes within academic programs. The relationships between these processes were demonstrated using the four proposed models as a case study.

Despite the old debate that doubted the applicability of the ISO standard to the educational process, our experience- reported in this paper- showed otherwise. The educational processes can be represented within the ISO 9001:2015 concepts of the process approach and the PDCA cycle. We are currently extending this study to apply the third concept of risk-based thinking on the educational process.

\section{REFERENCES}

[1] ISO, (2017). ISO Survey. Retrieved from https://www.iso.org/the-iso-survey.html

[2] ISO, (2008). ISO 9000 Introduction and Support Package: Guidance on the Concept and Use of the Process Approach for management systems. Retrieved from https://www.iso.org/files/live/sites/isoorg/files/archive/pdf/en/04_concept_and_use_of_the_process_a pproach_for_management_systems.pdf

[3] ISO, (2015). International Organization for Standardization, THE PROCESS APPROACH IN ISO 9001:2015. Retrieved from http://www.iso.org/tc176/sc02/public

[4] Pszenica, Y. (2001). Project Management and ISO 9001-An Integrative Approach Through Process Management. In Proceedings of the Project Management Institute Annual Seminars \& Symposium, Nashville, Tenn., USA. 
International Journal of Software Engineering \& Applications (IJSEA), Vol.10, No.2, March 2019

[5] Marques, P. A., Requeijo, J. G. (2009). SIPOC: A Six Sigma Tool Helping on ISO 9000 Quality Management Systems. In 3rd International Conference on Industrial Engineering and Industrial Management XIII. Barcelona-Terrassa: Congreso de Ingeniería de Organización.

[6] Moreland, N. \& Clark M., (1998) Quality and ISO 9000 in educational organizations, Journal Total Quality Management, Vol 9, No. 2, pp311-320.

[7] Thonhauser, T., \& Passmore, D. (2006). ISO 9000 in education: A comparison between the United States and England. Research in Comparative and International Education, 1(2), 156-173

[8] El Abbadi, L., Bouayad, A., Lamrini, M. (2013). ISO 9001 and the Field of Higher Education: Proposal for an Update of the IWA 2 Guidelines. Quality Approaches in Higher Education, 4 (2), 14 19.

[9] ISO, (2007). ISO/IWA 2: Quality management systems - Guidelines for the application of ISO 9001:2000 in education. Retrieved from https://www.iso.org/obp/ui/\#iso:std:iso:iwa:2:ed-2:v1:en

[10] Ismail, K., \& Gadar, K. (2008). A Beneficiary-Driven and Recipient-Focused Program Using ISO 9001:2000 in Teaching and Learning in Malaysian University. The Journal of International Management Studies, 3 (2), 133-140.

[11] Gamboa, A. J., Melão, N. F. (2012). The impacts and success factors of ISO 9001 in education: Experiences from Portuguese vocational schools. International Journal of Quality \& Reliability Management, 29 (4), 384-401.

[12] Ariff, M., Zaidin, N., Sulong, N. (2007). Total Quality Management Implementation in Higher Education: Concerns and Challenges Faced by the Faculty. In Proceedings of the 12th International Conference on ISO 9000 and TQM, Taiwan: National Chin-Yi University of Technology.

[13] Levina, E. Y., Kamasheva, Y. L., Gazizova, F. S., Garayeva, A. K., Salpykova,I. M., Yusupova G., Kuzmin, N. (2015). A Process Approach to Management of an Educational Organization. Review of European Studies, 7 (4) 234-240.

[14] OMG, (2016). Object Management Group, Business Process Model \& Notation ${ }^{\mathrm{TM}}$ (BPMNTM): Resource Page. Retrieved from http://www.omg.org/bpmn

[15] Sommerville, I. (2016). Software Engineering, England: Pearson.

[16] J.A. Garcia-Garcia , J.G. Enriquez, F.J. Dominguez-Mayo (2019), Characterizing and evaluating the quality of software process modelling language: comparison of ten representative model-based languages, Computer Standards \& Interfaces. Vol 63, 52-66. 